\title{
O ENSINO DA ÁREA DE CONTROLE SOBRE A PERSPECTIVA DA COMPETÊNCIA: Experiência no Curso de Biblioteconomia da UFSC
}

\author{
Maria del Carmen R. Bohn, PhD. - Bohn@mbox1.ufsc.br. \\ Departamento de Ciências da informação/UFSC
}

\begin{abstract}
Resumo
$\mathrm{O}$ artigo apresenta algumas tendências da educação atual relacionando as demandas da globalização e dos avanços tecnológicos com a formação do profissional na Ciência da Informação. Introduz-se os conceitos de 'conhecimento' e de 'competência', mostrando como podem ser abordados em algumas das disciplinas do Currículo de Biblioteconomia, integrando aquilo que a literatura tem recentemente chamado de saber em oposição ao saber fazer. Conclui-se que a ação pedagógica, devido ao trabalho profissional em que os profissionais de biblioteconomia se envolvem, deve contemplar o desenvolvimento de ambos os saberes tanto nos conteúdos dos programas como nas interações dos alunos.
\end{abstract}

Palavras-chave: Desenvolvimento de Competências, Ciência da Informação; Formação do Profissional, Ciência da Informação; Ensino de Controle Bibliográfico

\begin{abstract}
This article, first, presents some tendencies on current education and relates the social demands of globalisation and technological advances to the education of professionals in Library and Information Science. Second, it introduces the concepts of "knowledge" and "competence", showing how they can be approached in some of the disciplines of Library and Information Science, and how they cam be integrated with the concepts of what literature has been calling recently as "knowing what" in opposition to "knowing how". The article concludes proposing that library programs, because of the professionals activities information science professionals will be involved in, should contemplate the development of both knowledges, "knowing what"- emphasising the development of academic skills, and "knowing how"- the ability to interpret knowledges for the solution of problems.
\end{abstract}

Keywords: Development of Competence, Library Science; Education of professionals, Library Science; Teaching, Library Science

\section{INTRODUÇ̃̃O}

O surgimento de novas tecnologias no tratamento e recuperação da informação e as mudanças que têm ocorrido no universo da ciência e tecnologia colocam o profissional de informação frente as mudanças do mercado de trabalho que exige uma série de conhecimentos e competências novas. O objetivo deste trabalho é fazer algumas reflexões sobre as mudanças no mercado de trabalho e a formação do profissional da Ciência da Informação dentro destas exigências.

\section{O PROFISSIONAL E O MERCADO DE TRABALHO}

Profissional é aquele que desenvolve um componente intelectual significativo de conhecimentos (saberes) e de competências (saber fazer), que o colocam na situação de prestar um serviço relevante a sociedade. Os serviços que a sociedade demanda do profissional de informação têm mudado em diferentes direções devido as necessidades criadas pelas mudanças sociais, culturais e tecnológicas. Esta situação coloca os profissionais da informação não só em competição com especialistas de outras áreas como, naturalmente, direciona as áreas da profissão por novos caminhos, e exige do profissional um elenco mais amplo de conhecimentos e competências, que o coloquem em um plano de igualdade, com os profissionais de outras áreas.

Em pesquisa conduzida na Inglaterra, (Clausen, 1990 p. 266-67) relata que a maior parte de oferta de trabalho dentro deste país exige 3 tipos de profissionais para atuar na área de informação:

- Bibliotecários que lidem com os serviços convencionais de organização;

- Especialistas em sistemas de informação que planejem sistemas para resolver os problemas de organização da informação;

- Pesquisadores e analistas da informação que tenham uma variedade de habilidades e conhecimentos para prover informação que responda às necessidades da organização.

Detlefsen (1992), por sua vez, relata os resultados de uma pesquisa realizada nos Estados Unidos. A autora analisa o mercado de trabalho com base nos anúncios publicados nos últimos seis meses de 1991, em 
periódicos e jornais tais como: The College \& Research Libraries News; The New York Times, Science e Chronicle of Higher Education. Inclui também na análise os anúncios colocados em várias listagens de bibliotecas de pesquisa e nos murais das Escolas de Biblioteconomia. Os resultados apontam claramente que a demanda de profissionais pode ser agrupada em três categorias:

- Especialistas de assunto com clara indicação de que embora exigido o título de Mestrado em Ciência da Informação (M.L.S) ou equivalente, o conhecimento de assunto é mais importante que o diploma ou certificado;

- Especialistas em tecnologia, que possam lidar com os aspetos relativos a automação de bibliotecas, recursos eletrônicos e gerenciamento de sistemas de informação. Dentro desta categoria, pode-se distinguir a demanda por bibliotecários para lidar com tarefas diárias relativas a manutenção do computador, programação e análise de sistema. Alem disso, há uma demanda para especialistas que possam lidar tanto com as novas tecnologias da informação como com as responsabilidades de gerenciamento e planejamento estratégico;

- Especialistas em gerenciamento, para assumir posições de chefe, diretor, etc., não requerendo-se para esta posição as credenciais de bibliotecário.

A demanda, no Brasil por profissionais com competências na área de gestão de informação, principalmente, é confirmada por Cunha (1998). A autora analisa a oferta de emprego no Brasil, entre 19911995, baseia sua análise nas ofertas de emprego publicadas em jornais brasileiros de São Paulo (Folha de São Paulo e o Estado de São Paulo) e Rio de Janeiro (Jornal do Brasil) e o Globo), e nas entrevistas e questionários respondidos por um grupo de empregadores e de profissionais.

O estudo de Nastri e Souza (1996, p.198) por sua vez, conduzido entre bibliotecários atuantes principalmente em bibliotecas universitárias no interior do Estado de São Paulo, verificou que no processo de seleção, o diploma é a variável mais importante. No entanto, os empregadores também exigem dos candidatos potenciais ao emprego, experiência, conhecimentos de informática, língua estrangeira, principalmente inglês e conhecimentos de administração, entre outros.

Assim, a natureza e o mercado de trabalho do profissional da informação reagem às necessidades da demanda social e são sensíveis à utilização de novas tecnologias, aos novos meios de transmissão e comunicação, ao aumento crescente de publicações, as novas necessidades e informatização dos usuários, e à necessidade de um aumento de capital para custear os gastos emergentes da aplicação de novas tecnologias. Os contrastes entre as diferentes unidades de informação e as desigualdades nas condições e exigências no trabalho, certamente são fatores que também influenciam o mercado de trabalho do profissional de informação brasileiro.

Os resultados das pesquisas de Clausen (1990), Detlefsen (1992), Cunha (1998) e Nastri e Souza (1996) apontam claramente a demanda por habilidades empresarias e tecnológicas. No entanto, se os profissionais de informação que exercem atividades de gerenciamento estiverem limitados em sua autonomia e direito de julgar o desenvolvimento de seu próprio trabalho, e se dentro de certos limites, não tiverem a habilidade e autonomia para decidir o trabalho a ser feito e como fazê-lo, seu papel profissional e sua competitividade perante profissionais de outras áreas fica muito limitado.

\section{ABORDAGEM DO ENSINO POR COMPETÊNCIAS NA ÁREA DE CONTROLE}

As novas diretrizes curriculares dos cursos de graduação de Biblioteconomia do Brasil, refletem a preocupação das instituições de ensino de assumir as novas tendências da área e se organizarem dentro da perspectiva da interdisciplinaridade.

Há preocupação das Escolas de Biblioteconomia e Ciência da Informação em nível de graduação, de estabelecer um equilíbrio entre educação e treinamento. Esto é claramente percebido na literatura brasileira sobre currículos. Não fica claro, no entanto, como as escolas estão abordando o ensino para preparar os alunos a enfrentarem as demandas da profissão, pois, não temos encontrado literatura alguma que nos ajude a identificar este aspecto. A Associação Brasileira de Escolas de Biblioteconomia e Documentação (ABEBD), tem promovido vários encontros de professores para tratar das diferentes matérias do Currículo Mínimo de Biblioteconomia. Porém, essas discussões ficam concentradas nos conteúdos programáticos das disciplinas sem dedicar nenhuma atenção às formas de conduzir o ensino/aprendizagem

Como formar profissionais para um pais como o Brasil onde os contrastes, as condições e exigências de trabalho do profissional de informação são desiguais? Onde não são poucos os estudantes que vêm o curso apenas como uma forma de melhoria de salário ou como uma etapa preparatória para seu treinamento dentro do serviço? Onde as desistências são altas, as escolas estão mal equipadas e grande parte de literatura da área se apresenta em línguas diferentes do Português nas quais os alunos não tem competência lingüística apropriada? Como formar profissionais que possuam as competências necessárias para assistir todos os usuários que atuam em diversas áreas?

Durante algum tempo tenho acreditado que o ensino de qualidade poderia ser definido como: "preparar as aulas adequadamente, seguir o plano de ensino, apresentar o conteúdo proposto, responder às perguntas dos

Enc. Bibli: R. Eletr. Bibliotecon. Ci. Inf., ISSN 1518-2924, Florianópolis, Brasil, n.8, p.16-19, 1999. 
alunos, realizar as avaliações e ter tempo disponível para orientá-los nas tarefas estabelecidas”. Acreditava também, por exemplo, que o aprendizado seqüencial de conhecimentos na área de controle (para definição da área de controle ver: Bohn e Brighenti, 1998, p.2), provocaria espontaneamente sua integração operacional em uma competência de saber fazer. Esta abordagem disciplinar certamente difere da abordagem do ensino por competências que tem como meta: "antes fazer aprender do que ensinar" (Perrenoud, 1999, p.53).

A literatura tem recentemente retomado a discussão sobre o papel da escola na formação do profissional. Por um lado, a academia sempre se preocupou com o desenvolvimento do conhecimento historicamente acumulado, formando alunos cultos, mas não necessariamente preparados para solucionar os problemas da vida real. Isto ficava para ser aprendido no próprio emprego. Por outro lado, com a globalização o distanciamento da escola com o mundo do trabalho tornou-se mais evidente e em resposta a este distanciamento desenvolveram-se metodologias de integração entre a escola e a empresa, por exemplo, e o saber fazer - lidar com situações do mundo real, tornou-se também uma preocupação da escola. O dilema entre orientar a escola para uma formação mais humanista ou profissional tornou-se então um debate central na educação. Em algumas áreas a transformação do saber para o saber fazer tornou-se mais premente.

As mudanças de objetivos da escola também trouxeram uma nova terminologia que expressassem os novos conceitos. Competência e conhecimento são dois termos chaves para este debate. Competência foi definida como "A capacidade de agir eficazmente em um determinado tipo de situação, apoiada em conhecimentos, mas sem limitar-se a eles" (Perrenoud,1999 p.7). Dentro desta linha de raciocínio, os conhecimentos, por exemplo, de classificação, indexação, catalogação, normalização, bases de dados e tecnologias que o profissional de informação possui são conhecimentos necessários ao desenvolvimento de sua competência no campo de controle. Cada usuário que chega à biblioteca tem necessidades de informação diferenciadas e para atendê-lo eficazmente, o profissional precisa fazer uso de sua memória, resgatar as teorias pertinentes, as rotinas conhecidas e realizar operações mentais complexas de interpretação, interpolação e fazer uso de sua capacidade inferencial. Conhecimentos, por sua vez podem ser definidos como os "determinantes para identificar e resolver problemas para preparar e formar decisões, no entanto eles só tem valor quando estão disponíveis no momento certo e em sintonia com a situação” (idem: p.53).

Tendo esta problemática em mente, tenho desenvolvido uma nova abordagem no ensino da disciplina Registros do Conhecimento III. Em vez de conduzir aulas tradicionais em que o professor apresenta um conjunto de conteúdos e de tarefas sobre situações simuladas e fictícias a serem resolvidas pelos alunos, organizou-se juntamente com estes, um conjunto de projetos de levantamentos bibliográficos em fontes impressas e automatizadas. Estes projetos foram organizados e planejados sobre as necessidades reais dos usuários, professores, pesquisadores e alunos de mestrado. As necessidades de informação desta clientela forma explicitadas através de solicitações. Durante a discussão dos projetos de levantamentos bibliográficos incentivou-se o debate, a contribuição individual do aluno e foi salientada a importância do comprometimento dos alunos com o projeto e com as tarefas do grupo. Reuniões periódicas de acompanhamento entre alunos, pesquisadores (usuários) e a professora permitiram ao longo de execução dos projetos a avaliação de sua pertinência e a solução conjunta dos problemas encontrados. Objetivou-se através desta metodologia participativa e do envolvimento dos alunos construir conhecimentos e pelas interações reiteradas desenvolver a competência dos alunos na área definida.

O confronto regular dos estudantes com situações reais e concretas, em oposição aos exercícios artificiais e descontextualizados, faz maior sentido, pois exige que os alunos estabeleçam uma interação entre os conhecimentos construídos e a solução dos problemas propostos. Este confronto também leva a despertar o interesse e a responsabilidade do aluno, tendo como conseqüência a procura de informações, o uso estratégico de conhecimentos e experiências na solução de problemas. A definição das palavras chave pelos pesquisadores (usuários) evita o possível desgaste e desânimo dos estudantes, visto que a maioria têm dificuldades com línguas estrangeiras e com a definição dos assuntos. A avaliação esteve presente ao longo dos projetos, com o objetivo de apreciar as dificuldades e progressos dos alunos com vistas a orientá-los. Ressaltou-se a importância da contribuição de cada um para o progresso do projeto coletivo. Inicialmente, notou-se resistência dos estudantes, mas depois de um certo tempo, a maioria tornou-se cooperativa e solidária no desenvolvimento dotrabalho.

Na minha prática de ensino, considerava normal e até necessário antecipar as respostas a perguntas que não foram feitas, até perceber que a construção de competências significa também: "aceitar aportar o mínimo requerido, sabendo-se que o restante virá depois, oportunamente”(Perrenoud, 1999, p.55-56). Isto é, o saber e o saber fazer fazem parte de um processo de construção e de uma aprendizagem que o aluno inicia na sala de aula mas que se consolida na vivência profissional. No entanto, se a escola somente desenvolver o saber estará preparando um profissional que não saberá lidar com o mundo real e sem a competência para instrumentalizarse. 


\section{CONCLUSÃO}

Apresentamos algumas reflexões sobre as exigências que as mudanças econômicas e tecnológicas introduzem no campo de trabalho do profissional de informação. Foi visto que no Brasil e no estrangeiro existe demanda por bibliotecários com habilidades empresarias e tecnológicas. E que uma das tendências nos centros de informação do primeiro mundo é de recrutar além de bibliotecários, profissionais competentes em outras áreas . No entanto, este fato não deve ser visto como uma ameaça a profissão mas sim como uma oportunidade para enriquecê-la com a perspectiva multidisciplinar trazida por profissionais de outras áreas. A absorção das várias tecnologias assim como os grupos que as servem é fundamental para a sobrevivência da profissão. É difícil imaginar que exista uma única área capaz de preparar profissionais que atendam as exigências de um serviço de informação para um universo tão amplo como o da ciência e tecnologia. A emergência de novas responsabilidades dentro do campo da informação exigem do profissional uma atuação e um preparo mais competitivo e diversificado. Prepará-lo adequadamente, em termos de conhecimentos e competências, é o nosso desafio. A abordagem do ensino por competências tem se mostrado eficaz quanto ao ensino de Controle dos Registros do Conhecimento, pois mobiliza os diversos recursos cognitivos, as experiências do aluno e os associa a uma postura reflexiva, permitindo também uma participação mais efetiva do aluno no processo de aprendizagem.

Os cursos de Biblioteconomia em nível de graduação e de pós-graduação e as entidades de classe devem assumir as novas tendências da área de informação e se organizar dentro da perspectiva de interdisciplinaridade e de atualização constante com vistas a um novo perfil do profissional de informação. A tecnologia aplicada à informação muda tão rapidamente, que a atualização do conhecimento torna-se necessária mesmo para os profissionais considerados mais competentes. $\mathrm{O}$ aprender a aprender torna-se o objetivo mais recente na formação do profissional. Desenvolver as competências para lidar com a realidade, o imprevisto e as diferenças individuais dos usuários devem ser algumas das preocupações das escolas de biblioteconomia no Brasil.

\section{REFERÊNCIAS BIBLIOGRÁFICAS}

BOHN, M. del Carmen e BRIGHENTI, C. N. Produção de material instrucional para o ensino de fontes de informação. Encontros BIBLI. Florianópolis, n. 5, p. 117, abril 1998.

CLAUSEN, H. The future information professional: old wine in new bottles? Part One. Libri, v. 40, n.2, p. 265-277, Dec. 1990.

CUNHA, M. V. da. L'emergence des nouveaux professionnels de l'information: formation, compétences, marché: etude compareé des situations brésilienne et française. Paris: Conservatoire national das arts et metiers, 1998. 321p.

DETLEFSEN, E.G. Specialists as professionals in research libraries: an overview of trends and an analysis of job announcements. Library Trends, v. 41, n.2, p.187-97, Fall 1992.

PERRENOUD, P. Construir as competências desde a escola. Porto Alegre: Artes Médicas Sul,1999.

SOUZA, M. A. de, NASTRI, R. M. Análise do mercado de trabalho do bibliotecário no interior do Estado de São Paulo. Perspectiva em Ciência da Informação. Belo Horizonte, v.1, n.2, p.189-206, jul./dez. 1996. 